\title{
Epidemic and virulence characteristic of Shigella spp. with extended-spectrum cephalosporin resistance in Xiaoshan District, Hangzhou, China
}

Chuan-Ling Zhang ${ }^{1 \dagger}$, Qing-Zhong Liu ${ }^{2 * \dagger}$, Juan Wang ${ }^{2}$, Xu Chu' ${ }^{1}$ Li-Meng Shen ${ }^{1}$ and Yuan-Yu Guo ${ }^{1}$

\begin{abstract}
Background: Shigellae have become increasingly resistant to the extended-spectrum cephalosporin (ESC) worldwide and pose a great challenge to anti-infection treatment options. The purpose of this study was to determine the resistance, cephalosporin resistance mechanisms, virulence characteristic and genotype of ESC-resistant Shigella.

Methods: From 2008 to 2012, Shigella isolates collected from diarrhea patients were detected for antibiotics sensitivity by disk diffusion, cephalosporin resistance determinants and virulence genes using polymerase chain reaction (PCR) and genotyping through enterobacterial repetitive intergenic consensus sequence PCR (ERIC-PCR).

Results: A total of 356 Shigella isolates were gathered, and 198 (55.6\%, 58 S. flexneri and 140 S. sonnei) were resistant to ESC. All ESC-resistant isolates were susceptible to imipenem, and only $0.5 \%$ isolate was resistant to piperacillin/tazobactam. ESC-resistant S. flexneri showed high degrees of resistance to ampicillin (100\%), ampicillin/sulbactam (96.6\%), piperacillin (100\%), trimethoprim/sulfamethoxazole (74.1\%), ciprofloxacin (74.1\%), levofloxacin (53.4\%), ceftazidime (58.6\%) and cefepime (58.6\%). ESC-resistant S. sonnei exhibited high resistance rates to ampicillin (100\%), piperacillin (100\%) and trimethoprim/sulfamethoxazole (96.4\%). Cephalosporin resistance genes were confirmed in 184 ESC-resistant isolates. bla $a_{C T X-M}$ types (91.8\%, mainly bla $a_{C T X-M-14}$, bla $a_{C T X-M-15}$ and $\left.b a_{C T X-M-57}\right)$ were most prevalent, followed by bla $a_{O X A-30}(26.3 \%)$. Over 99.0\% ESC-resistant isolates harbored virulence genes ial, ipaH, virA and sen. However, set1 were more prevalent in ESC-resistant S. flexneri isolates than in S. sonnei isolates. ERIC-PCR results showed that 2 and 3 main genotypes were detected in ESC-resistant S. flexneri and S. sonnei, respectively.

Conclusion: Our findings indicated that a high prevalence of ESC-resistant Shigella mediated mainly by bla $a_{C T X-M}$ with stronger resistance and virulence, and the existence of specific clones responsible for these Shigella infection in the region studied.
\end{abstract}

Keywords: Shigella, Extended-spectrum cephalosporin, Resistance, Cephalosporin resistance mechanism, Virulence markers, Genotyping

\footnotetext{
* Correspondence: zzzz2000@tom.com

${ }^{\dagger}$ Equal contributors

${ }^{2}$ Department of Clinical Laboratory, Shanghai First People's Hospital, School of Medicine, Shanghai Jiaotong University, 100 Haining Road, Shanghai 200080, People's Republic of China

Full list of author information is available at the end of the article
} 


\section{Background}

Shigellosis continues to be a major public health problem in non-industrialized countries. It was reported that about 91 million cases of shigellosis occurred, with 414,000 people dying in Asia annually [1]. In China, the morbility of Shigella infections each year is unusually high. Wang et al. [2] have reported that in 2000 0.8-1.7 million episodes of shigellosis occurred in seven different geographical regions, China.

For shigellosis, antibiotic therapy can reduce the duration and severity of the illness [3]. However, with the long-term overuse of antimicrobials, the resistant Shigella has prevailed all over the word, and production of extendedspectrum $\beta$-lactamases (ESBLs) or AmpC enzymes is one of the most important resistance mechanisms. In China extended-spectrum cephalosporin (ESC)-resistant Shigella spp. has also been described in recent years [3-7]. However, as China has a vast territory area, the spectrum of antimicrobial resistance and the mechanisms of resistance may vary in different regions. Therefore, it is necessary to explore the variations of ESC resistance in clinical isolates of Shigella spp. from different geographical areas.

The ability of Shigella spp. to cause shigellosis is attributed to the expression of arrays of virulence genes associated with colonization, invasion/penetration and toxin-mediated disease, such as the invasion-associated locus (ial), the invasion plasmid antigen $\mathrm{H}$ gene (ipaH), Shigella enterotoxin 1 (ShET-1) gene (set1A and set1B), Shigella enterotoxin 2 (ShET-2) gene (sen) and virA gene $[8,9]$. Estimating the existence of virulence determinants in Shigella would help us better understand its pathogenicity. However, investigations into clinical Shigella spp. virulence factors are still rare in the world.

The purpose of this study was to investigate the resistance, the cephalosporin resistance mechanisms and the prevalence of putative virulence genes in ESC-resistant Shigella from patients with dysentery in Xiaoshan District, suburban of Hangzhou city, Zhejiang province, China. Finally we further ascertained the genotypes of these strains by ERIC-PCR (enterobacterial repetitive intergenic consensus sequence PCR) typing.

\section{Methods}

\section{Bacterial isolates}

Between January 2008 and December 2012, a total of 356 nonduplicate Shigella isolates were obtained from the faeces of different diarrhea patients at Zhejiang Xiaoshan hospital, Hangzhou City, Zhejiang Province, China. All isolates were identified by VITEK 60 microbial identification system (BioMérieux Corp., Lyon, France) and serotyped using commercial antisera (Lanzhou Institute of Biological Products, Lanzhou, China). Isolates studied were taken as part of standard patient care. Because of being focused on bacteria, no ethical approval was required for this study.

\section{Antimicrobial susceptibility testing}

The Shigella isolates were detected for antibiotic susceptibility by Kirby-Bauer method for the following antibiotics (Oxoid, Hampshire, UK), according to Clinical and Laboratory Standards Institute (CLSI), 2012 [10]: ampicillin (AMP), piperacillin (PIP), ciprofloxacin (CIP), trimethoprim/ sulfamethoxazole (SXT), levofloxacin (LEV), ampicillin/ sulbactam (SAM), piperacillin/tazobactam (TZP), imipenem (IMP), cefotaxime (CTX), ceftazidime (CAZ), cefepime (FEP) and cefoxitin (FOX). ESC-resistant organisms were defined as isolates showing resistance or intermediate to cefotaxime (zone diameter $\leq 25 \mathrm{~mm}$ ) or ceftazidime (zone diameter $\leq 20 \mathrm{~mm}$ ) or cefepime (zone diameter $\leq 17 \mathrm{~mm}$ ) [10]. Escherichia coli ATCC 25922 was used for antibiotic susceptibility testing quality control.

\section{ESBL and AmpC detection}

ESC-resistant isolates were screened for ESBL production by the phenotypic confirmatory test according to CLSI [10]. AmpC examination was performed by the threedimensional extract test as described by Philip et al. [11] for cefoxitin resistant or intermediate isolates.

\section{$\mathrm{ESBL}, \mathrm{AmpC}$ and virulence genes amplification}

Detection of the ESBL genes $\left(b l a_{T E M}, b l a_{\text {OXA }}, b l a_{C T X-M-1,2,8,9}\right.$ and $\left.b l a_{S H V}\right)$ and virulence determinants (ial, iapH, set $1 A$, set $1 B$, sen and virA) were performed by PCR for ESC-resistant isolates, as described previously $[3,12,13]$. AmpC genes (bla $a_{M O X}, b l a_{C I T}, b l a_{D H A}, b l a_{A C C}, b l a_{E B C}$ and $b\left(a_{F O X}\right)$ were examined by multiplex-PCR for cefoxitin resistant or intermediate isolates according to Perez-Perez et al. [14]. Sequences of the primers were given in Table 1. The PCR products for ESBL and AmpC genes were sequenced on both DNA strands with ABI 3730XL sequencer (Perkin-Elmer) by Shanghai Sangon Biotech. The nucleotide sequences were analyzed by the BLAST program. For virulence genes, a representative amplicon for the each gene detected was also sequenced to validate that primers amplified the target genes.

\section{ERIC-PCR}

ERIC-PCR was carried out on ESC-resistant Shigella isolates using primer ERIC2: 5'-AAGTAAGTGACTGGGGT GAGCG-3', as described by Navia et al. [15].

\section{Clinical data}

Clinical information of the patients was collected from the case notes. The data included date of onset, symptoms (such as times of diarrhea, nausea, bellyache, vomiting, fever and bloody stools), results of microscopic examination of stool (white blood cell and red blood cell), treatment and duration of illness. 
Table 1 Primers used for PCR to detect Shigella resistance and virulence genes

\begin{tabular}{lll}
\hline Primer Sequence $\left(5^{\prime}-3^{\prime}\right)$ & $\begin{array}{l}\text { Amplicon Reference } \\
\text { size }(b p)\end{array}$
\end{tabular}

ESBL genes

CTX-M-1 F-GGCCCATGGTTAAAAAATCA group CTGC

891

R-CCGTTTCCGCTATTACAAACC GTTG

\section{CTX-M-2 F-CTCAGAGCATTCGCCGCTCA}

group

R-CCGCCGCAGCCAGAATATCC

CTX-M-8 F-ATGATGAGACATCGCGTTAAC group

R-CGGTGACGATTTTCGCGGCAG

CTX-M-9 F-GTGACAAAGAGAGTGCAACGG group

R-ATGATTCTCGCCGCTGAAGCC

OXA group F-ACACAATACATATCAACTTCGC R-AGTGTGTTTAGAATGGTGATC

SHV group F-GCCTITCGGCCTTCACTCAAG R-TTAGCGTTGCCAGTGCTCGATCA

TEM group F-ATAAAATTCTTGAAGACGAAA

R-GACAGTTACCAATGCTTAATC

AmpC $\beta$-lactamase genes

MOX group F-GCTGCTCAAGGAGCACAGGAT R-CACATTGACATAGGTGTGGTGC

CIT group F-TGGCCAGAACTGACAGGCAAA R-TTTCTCCTGAACGTGGCTGGC

DHA group F-AACTITCACAGGTGTGCTGGGT R-CCGTACGCATACTGGCTTTGC

ACC group F-AACAGCCTCAGCAGCCGGTTA R- TTCGCCGCA ATCATCCCTAGC

EBC group F-TCGGTAAAGCCGATGTTGCGG R- CTTCCACTGCGGCTGCCAGTT

FOX group F- AACATGGGGTATCAGGGAGATG R- CAA AGCGCGTAACCGGATTGG Virulence gene

$\begin{array}{lll}\text { ial } & \text { F-CTGGATGGTATGGTGAGG } & 320 \\ \text { ipaH } & \text { R-GGAGGCCAACAATTATTCC } & \\ & \text { F-TGGAAAAACTCAGTGCCTCT } & 423 \\ \text { set/A } & \text { R-CCAGTCCGTAATTCATTCT } & \\ & \text { F-TCACGCTACCATCAAAGA } & 309 \\ \text { set/B } & \text { R-TATCCCCCTITGGTGGTA } & \\ & \text { F-GTGAACCTGCTGCCGATATC } & 147 \\ \text { sen } & \text { R-ATTGTGGATAAAATGACG } & \\ & \text { F-ATGTGCCTGCTATTATTAT } & 799 \\ & \text { R-CATAATAATAAGCGGTCAGC } & \end{array}$

R-CATAATAATAAGCGGTCAGC
Table 1 Primers used for PCR to detect Shigella resistance and virulence genes (Continued)

\begin{tabular}{lll}
\hline virA & F-CTGCATTCTGGCAATCTCTTCA & 215 \\
& CATC \\
& R-TGATGAGCTAACTTCGTAAGCC \\
& CTCC
\end{tabular}

\section{Statistical analysis}

Pearson's chi-square test or Fisher's exact test if necessary was used to analyze the differences of antibiotics resistance, and virulence genes, and the relationship of virulence factors, resistance and ERIC-PCR genotypes (SPSS 11.5). All statistical tests were two tailed, with $p<0.05$ considered statistically significant.

\section{Results}

Distribution of Shigella spp.

Among 356 Shigella isolates, S. sonnei was the most prevalent species $(\mathrm{n}=244,68.5 \%, 244 / 356)$, followed by S. flexneri ( $\mathrm{n}=112,31.5 \%, 112 / 356)$. No sample was positive for S. dysenteriae and S. boydii. In S. flexneri, seven different serotypes were found: 63 type 2a, 15 type 2c, 18 type 4c, 6 type 2b, 5 type 1a, 3 type $\mathrm{x}$ and 2 type 3a. $35.7 \%(40 / 112)$ of S. flexneri and $47.1 \%(115 / 244)$ of S. sonnei cases were found among patients under 5 years old; $20.5 \%$ (23/112) of S. flexneri and $23.4 \%$ (57/244) of $S$. sonnei isolates were from victims aged from 5 to 14 years; $43.8 \%(49 / 112)$ of S. flexneri and $29.5 \%$ $(72 / 244)$ of $S$. sonnei isolates were from patients aged $\geq 15$ years.

\section{Antimicrobial resistance}

Of the 356 Shigella isolates, 198 (55.6\%, 58 S. flexneri and $140 \mathrm{~S}$. sonnei) were resistant to cefotaxime, 59 (16.6\%) to ceftazidime, 66 (18.5\%) to cefepime (Table 2). The strains with resistance to ceftazidime or cefepime were all resistant to cefotaxime. Thus, these cefotaxime resistant strains were referred to as ESC-resistant isolates in this study. In addition, in these ESC-resistant isolates, $8(2.2 \%)$ were resistant or intermediate to cefoxitin.

Compared to cefotaxime susceptible $S$. flexneri isolates, the ESC-resistant $S$. flexneri isolates were more resistant to PIP (100\% versus $85.2 \%, p=0.002)$, SAM $(96.6 \%$ versus $85.2 \%, p=0.035)$, SXT (74.1\% versus $46.3 \%, p=0.003)$, CAZ $(58.6 \%$ versus $0 \%, p<0.001)$ and FEP $(58.6 \%$ versus $0 \%, p<0.001)$. In S. sonnei, the ESC-resistant strains were more resistant to AMP (100\% versus $95.2 \%, p=0.009)$, PIP $(100 \%$ versus $51.9 \%, p<0.001)$, SAM $(24.3 \%$ versus $0 \%$, $p<0.001)$, CAZ $(17.9 \%$ versus $0 \%, p<0.001)$ and FEP $(22.9 \%$ versus $0 \%, p<0.001)$ than the cefotaxime susceptible isolates (Table 2). Compared to ESC-resistant S. sonnei isaolates, the ESC-resistant $S$. flexneri isolates were significantly 
Table 2 Antibiotic resistance of ESC-resistant and susceptible Shigella isolates

\begin{tabular}{|c|c|c|c|c|c|c|c|c|}
\hline \multirow{3}{*}{ Antibiotic } & \multicolumn{7}{|c|}{ Number of isolates resistant to antibiotics (\%) } & \multirow{3}{*}{$\begin{array}{c}\text { ESC-resistant } \\
\text { S. flexneri vs ESC-resistant } \\
\text { S. sonnei ( } p \text { value) } \\
\end{array}$} \\
\hline & \multirow[b]{2}{*}{$\begin{array}{c}\text { Total } \\
(n=356)\end{array}$} & \multicolumn{3}{|c|}{ S. flexneri $(n=112)$} & \multicolumn{3}{|c|}{ S. sonnei $(\mathrm{n}=244)$} & \\
\hline & & $\begin{array}{l}\text { ESC-resistant } \\
\quad(n=58)\end{array}$ & $\begin{array}{c}\text { Cefotaxime } \\
\text { susceptible } \\
(n=54)\end{array}$ & $\begin{array}{l}\text { ESC-resistant } \\
\text { vs cefotaxime } \\
\text { susceptible } \\
\text { ( } p \text { value })\end{array}$ & $\begin{array}{l}\text { ESC-resistant } \\
\quad(n=140)\end{array}$ & $\begin{array}{c}\text { Cefotaxime } \\
\text { susceptible } \\
(n=104)\end{array}$ & $\begin{array}{l}\text { ESC-resistant } \\
\text { vs cefotaxime } \\
\text { susceptible } \\
\text { ( } p \text { value) }\end{array}$ & \\
\hline AMP & $\begin{array}{c}348 \\
(97.8)\end{array}$ & $58(100)$ & $51(94.4)$ & 0.069 & 140(100) & $99(95.2)$ & 0.009 & NA \\
\hline PIP & $\begin{array}{l}298 \\
(83.7)\end{array}$ & $58(100)$ & $46(85.2)$ & 0.002 & 140(100) & $54(51.9)$ & $<0.001$ & NA \\
\hline SAM & $\begin{array}{c}136 \\
(38.2)\end{array}$ & $56(96.6)$ & $46(85.2)$ & 0.035 & $34(24.3)$ & $0(0.0)$ & $<0.001$ & $<0.001$ \\
\hline TZP & $1(0.3)$ & $1(1.7)$ & $0(0.0)$ & 3.332 & $0(0.0)$ & $0(0.0)$ & NA & 0.119 \\
\hline CAZ & 59 (16.6) & $34(58.6)$ & $0(0.0)$ & $<0.001$ & 25(17.9) & $0(0.0)$ & $<0.001$ & $<0.001$ \\
\hline FEP & 66 (18.5) & $34(58.6)$ & $0(0.0)$ & $<0.001$ & $32(22.9)$ & $0(0.0)$ & $<0.001$ & $<0.001$ \\
\hline FOX & $8(2.2)$ & $3(5.2)$ & $0(0.0)$ & 0.090 & $5(3.6)$ & $0(0.0)$ & 0.056 & 0.618 \\
\hline IPM & $0(0.0)$ & $0(0)$ & $0(0.0)$ & NA & $0(0.0)$ & $0(0.0)$ & NA & NA \\
\hline SXT & $\begin{array}{c}304 \\
(85.4)\end{array}$ & $43(74.1)$ & $25(46.3)$ & 0.003 & 135(96.4) & 101(97.1) & 0.766 & $<0.001$ \\
\hline CIP & $86(24.2)$ & $43(74.1)$ & $39(72.2)$ & 0.819 & $3(2.1)$ & $1(1.0)$ & 0.485 & $<0.001$ \\
\hline LEV & $57(16.0)$ & $31(53.4)$ & $20(37.0)$ & 0.081 & $3(2.1)$ & $3(2.9)$ & 0.692 & $<0.001$ \\
\hline $\begin{array}{l}\beta \text {-lactam } \\
\text { antibiotic }+ \\
\text { SXT + CIP or } \\
\text { LEV }\end{array}$ & 69 (19.4) & $36(62.1)$ & $23(42.6)$ & 0.039 & $6(4.3)$ & $4(3.8)$ & 0.864 & $<0.001$ \\
\hline
\end{tabular}

AMP, ampicillin; PIP, piperacillin; SAM, ampicillin/sulbactam; TZP, piperacillin/tazobactam; FEP, cefepime; FOX, cefoxitin; IMP, imipenem; SXT, trimethoprim/ sulfamethoxazole; CIP, ciprofloxacin; LEV, levofloxacin.

$p<0.05$ were considered statistically significant.

NA, not available.

more likely to be resistant to CAZ (58.6\% versus $17.9 \%$, $p<0.001)$, FEP $(58.6 \%$ versus $22.9 \%, p<0.001)$, CIP (74.1\% versus $2.1 \%, p<0.001)$ and LEV (53.4\% versus $2.1 \%, p<0.001)$, and less likely to be resistant to SXT (74.1\% versus $96.4 \%, p<0.001)$. No Shigella isolates were resistant to IMP, and Only one S. flexneri isolates was resistant to TZP (Table 2).

\section{Multiresistance among ESC-resistant Shigella isolates}

Among the 356 Shigella isolates, 69 (36 ESC-resistant $S$. flexneri, 23 cefotaxime susceptible S. flexneri, 6 ESCresistant $S$. sonnei and 4 cefotaxime susceptible S. sonnei) were multidrug resistant (MDR, resistant to 3 or more classes of antimicrobial agents), and the multi-resistance was more frequent among $S$. flexneri isolates than among S. sonnei isolates (Table 2).

\section{Production of ESBL and AmpC}

The phenotypic confirmatory test displayed that $96.0 \%$ (190/198) ESC-resistant isolates were ESBLs positive (Table 3). Of 8 cefoxitin resistant or intermediate isolates, 2 were the three-dimensional extract test positive.

\section{Distribution of ESBL and AmpC genes}

Of the 198 ESC-resistant isolates, 105 (53.0\%) were positive for $b l a_{C T X-M-14}, 28$ (14.1\%) for bla $a_{C T X-M-15}, 22$ (13.6\%) for $b l a_{C T X-M-57}, 8$ (4.0\%) for $b l a_{C T X-M-28}, 7$ (3.3\%) for $b l a_{C T X-M-22}$, $52(26.3 \%)$ for bla $a_{O X A-30}, 1(0.5 \%)$ for $b l a_{C M Y-2}$, and $1(0.5 \%)$ for $b a_{D H A-1} ; 28$ (14.1\%) isolates carried non-ESBL gene $b l a_{T E M-1} ; 8(4.0 \%)$ strains were negative for all $\beta$-lactamase genes detected. No isolate hosted bla $a_{S H V}, b l a_{A C C}, b l a_{E B C}$ and $b a_{F O X}$ genes. And $44(23.2 \%)$ isolates were found to harbor $\geq 2 \beta$-lactamase genes (Table 3 ).

\section{Distribution of virulence genes}

All ESC-resistant Shigella isolates harbored the ial, ipaH and virA genes. The gene sen existed in $99.0 \%$ Shigella isolates. The genes set $1 A$ and $\operatorname{set} 1 B$ were more prevalent in S. flexneri strains than in S. sonnei isolates $(p<0.05)$ (Table 4). Of 198 ESC-resistant Shigella strains, 123 (S. sonnei isolates accounting for $92.7 \%, 114 / 123$ ) possessed the most prevalent virulence gene combination of $i a 1+i p a H+v i r A+s e n$, followed by the combination of $i a 1+i p a H+v i r A+\operatorname{set} 1 A+\operatorname{set} 1 B+\operatorname{sen}(S$. flexneri isolates accounting for $86.8 \%, 46 / 53$ ) (Table 4 ). 
Table 3 Distribution of genotypes of ESBL and AmpC in 198 ESC-resistant Shigella isolates

\begin{tabular}{|c|c|c|c|c|c|}
\hline \multirow{2}{*}{$\begin{array}{l}\text { ESBL phenotypic } \\
\text { confirmatory test (n) }\end{array}$} & \multicolumn{2}{|c|}{ Genotype } & \multirow{2}{*}{$\begin{array}{l}\text { S. flexneri } \\
(\mathrm{n}=58)\end{array}$} & \multirow{2}{*}{$\begin{array}{l}\text { S. sonnei } \\
(n=140)\end{array}$} & \multirow{2}{*}{$\begin{array}{c}\text { Total } \\
(n=198)\end{array}$} \\
\hline & ESBL or AmpC group & ESBL or AmpC gene & & & \\
\hline \multirow[t]{17}{*}{ Positive $(n=190)$} & \multirow[t]{4}{*}{ CTX-M-1 } & CTX-M-15 & 5 & 11 & 16 \\
\hline & & CTX-M-28 & 2 & 6 & 8 \\
\hline & & CTX-M-57 & 7 & 2 & 9 \\
\hline & & CTX-M-22 & 3 & 2 & 5 \\
\hline & CTX-M-9 & CTX-M-14 & 16 & 69 & 85 \\
\hline & TEM & TEM-1 & 2 & 4 & 6 \\
\hline & OXA & OXA-30 & 4 & 11 & 15 \\
\hline & CTX-M-1+CTX-M-9+OXA & CTX-M-15+CTX-M-14+OXA-30 & 1 & 0 & 1 \\
\hline & \multirow[t]{2}{*}{ CTX-M-1+ OXA+TEM } & CTX-M-22+OXA-30+TEM-1 & 0 & 2 & 2 \\
\hline & & CTX-M-57+ OXA-30+TEM-1 & 9 & 0 & 9 \\
\hline & CTX-M-1+ TEM & CTX-M-57+ TEM-1 & 2 & 0 & 2 \\
\hline & \multirow[t]{2}{*}{ CTX-M-1+ OXA } & CTX-M-57+ OXA-30 & 1 & 1 & 2 \\
\hline & & CTX-M-15+ OXA-30 & 2 & 8 & 10 \\
\hline & CTX-M-9+ OXA+TEM & CTX-M-14+ OXA-30+ TEM-1 & 1 & 3 & 4 \\
\hline & CTX-M-9+ OXA & CTX-M-14+ OXA-30 & 2 & 6 & 8 \\
\hline & CTX-M-9+ TEM & CTX-M-14+ TEM-1 & 0 & 6 & 6 \\
\hline & \multicolumn{2}{|c|}{ Not detect the ESBL or AmpC genotype } & 0 & 2 & 2 \\
\hline \multirow[t]{3}{*}{ Negative $(n=8)$} & CTX-M-9+CIT & CTX-M-14+CMY-2 & 0 & 1 & 1 \\
\hline & $\mathrm{CTX}-\mathrm{M}-1+\mathrm{DHA}+\mathrm{OXA}$ & CTX-M-15+OXA-30+DHA-1 & 1 & 0 & 1 \\
\hline & \multicolumn{2}{|c|}{ Not detect the ESBL or AmpC genotype } & 0 & 6 & 6 \\
\hline
\end{tabular}

\section{ERIC-PCR}

The 58 ESC-resistant S. flexneri isolates were classified into 8 types by ERIC-PCR. The distribution of isolates based on this epidemiological analysis was as follows: 26 isolates in type A, 11 isolates in type B, 5 isolates in type C, 4 isolates each in type D and type E, 3 isolates each in type $\mathrm{F}$ and type $\mathrm{G}$, and 2 isolates in type $\mathrm{H}$. Among the 140 ESC-resistant S. sonnei isolates, 13 different genotypes (type A to $\mathrm{M}$ ) were obtained. The major genotype was type A (66 isolates), followed by type B (19 isolates), type $\mathrm{C}$ (12 isolates), type $\mathrm{D}$ (8 isolates), type $\mathrm{E}$ (7 isolates), type $F$ (7 isolates), type $\mathrm{G}$ (6 isolates), type $\mathrm{H}$ (6 isolates), type I (3 isolates), type J (2 isolates), type $\mathrm{K}$ ( 2 isolates), type $\mathrm{L}$ ( 1 isolates) and type $\mathrm{M}$ ( 1 isolates).

Table 4 Prevalence and combination of virulence genes among 198 ESC-resistant Shigella isolates

\begin{tabular}{|c|c|c|c|c|c|c|c|c|c|c|c|c|}
\hline \multirow[t]{2}{*}{ Isolate } & \multirow[t]{2}{*}{ Serotype } & \multicolumn{6}{|c|}{ No. $(\%)$ of isolates that produced the following: } & \multicolumn{5}{|c|}{$\begin{array}{l}\text { No. (\%) of isolates that contained } \\
\text { the following combination of genes }\end{array}$} \\
\hline & & ial & ipaH & virA & set1A & $\operatorname{set} 1 B$ & sen & 1 & II & III & IV & $\mathbf{v}$ \\
\hline \multirow[t]{6}{*}{ S. flexneri $(n=58)$} & $1 a(n=2)$ & $2(3.4)$ & $2(3.4)$ & $2(3.4)$ & $0(0.0)$ & $0(0.0)$ & $2(3.4)$ & $0(0.0)$ & $2(3.4)$ & $0(0.0)$ & $0(0.0)$ & $0(0.0)$ \\
\hline & $2 \mathrm{a}(\mathrm{n}=37)$ & $37(63.8)$ & $37(63.8)$ & $37(63.8)$ & $36(62.1)$ & $36(62.1)$ & $37(63.8)$ & $0(0.0)$ & $1(1.7)$ & $0(0.0)$ & $0(0.0)$ & $36(62.1)$ \\
\hline & $2 b(n=2)$ & $2(3.4)$ & $2(3.4)$ & $2(3.4)$ & $0(0.0)$ & $0(0.0)$ & $2(3.4)$ & $0(0.0)$ & 2(3.4) & $0(0.0)$ & $0(0.0)$ & $0(0.0)$ \\
\hline & $2 c(n=5)$ & $5(8.6)$ & $5(8.6)$ & $5(8.6)$ & $0(0.0)$ & $0(0.0)$ & $5(8.6)$ & $0(0.0)$ & $5(8.6)$ & $0(0.0)$ & $0(0.0)$ & $0(0.0)$ \\
\hline & $4 c(n=12)$ & 12(20.7) & $12(20.7)$ & $12(20.7)$ & $10(17.2)$ & $10(17.2)$ & $12(20.7)$ & $0(0.0)$ & $2(3.4)$ & $0(0.0)$ & $0(0.0)$ & $10(17.2)$ \\
\hline & & $58(100)$ & $58(100)$ & $58(100)$ & $46(79.3)$ & $46(79.3)$ & $58(100)$ & $0(0.0)$ & $12(20.7)$ & $0(0.0)$ & $0(0.0)$ & $46(79.3)$ \\
\hline S. sonnei $(n=140)$ & & $140(100)$ & $140(100)$ & $140(100)$ & $12(8.6)$ & 19 (13.6) & 138(98.6) & $2(1.4)$ & $114(81.4)$ & $5(3.6)$ & $12(8.6)$ & $7(5.0)$ \\
\hline $\begin{array}{l}\text { S. flexneri vs S. sonnei } \\
\text { ( } p \text { value) }\end{array}$ & & NA & NA & NA & $<0.001$ & 0.003 & 0.360 & 0.364 & $<0.001$ & 0.603 & 0.021 & $<0.001$ \\
\hline Total & & 198(100) & 198(100) & 198(100) & $58(29.3)$ & $65(32.8)$ & $196(99.0)$ & $2(1.0)$ & $123(62.1)$ & $8(4.0)$ & $12(6.1)$ & $53(26.8)$ \\
\hline
\end{tabular}

$p<0.05$ were considered statistically significant.

I, ia $1+i p a H+v i r A ; I I, i a 1+i p a H+v i r+\operatorname{sen} ; I I I, i a 1+i p a H+v i r A+\operatorname{set} I A+\operatorname{sen} ; \mathrm{IV}, i a 1+i p a H+v i r A+\operatorname{set} I B+\operatorname{sen} ; \mathrm{V}, i a 1+i p a H+v i r A+\operatorname{set} I A+\operatorname{set} I B+\operatorname{sen}$.

NA, not available. 


\section{Discussion}

This investigation reported the prevalence and resistance of ESC-resistant Shigella, and the molecular analysis of cephalosporin resistance genes and virulence determinants in clinical isolates from Xiaoshan District, Hangzhou, China collected over a period of 5 years. In the economic undeveloped regions, S. flexneri is the most frequently isolated Shigella species. A similar situation also exists in China, according to previous data $[2,4,6,16-18]$. However, in our study $S$. sonnei was the most common cause of bacterial dysentery, which was consistent with the findings in industrialized countries. In recent years, the data from Kaengkhoi District of Thialand, Ho Chi Minh City of Vietnam, South Korea, Taiwan and the East, North and Northeast regions of China, which are the newly industrialized regions, also displayed a striking species shift from $S$. flexneri to $S$. sonnei [18-22]. Therefore, the species transition of shigellosis in the present study may be related to the economic growth in Xiaoshan District, suburban of Hangzhou city with higher economic indicators. Of course, other factors may also play a role and need further researches.

Through the resistance data analysis, we found that more than half of the S. flexneri and S. sonnei isolates were resistant to ESC (cefotaxime). Data from 8 Asian countries showed a high prevalence of resistance to the frontline antibiotics AMP (53.0\%) and SXT (81.0\%) among Shigella isolates [21]. However, the resistance rates to the both drugs among all our Shigella isolates were more higher (AMP, 97.8\%; SXT, 85.4\%), and were consistent with the data from other investigations, mainland China $[6,16,17]$. The data from Table 2 showed that SAM was not appropriate for the treatment of diarrhea caused by S. flexneri, regardless of the strains with ESC-resistance (96.6\%) or susceptibility (85.2\%); On the contrary, it can be used to prescribe for $S$. sonnei infections, especially for the cefotaxime susceptible strains. Although the resistance rate of Shigella to PIP was high (83.7\%) in this study, TZP was of very high anti-Shigella activity (Table 2).

If the inhibition zone diameter of CAZ is $\geq 21 \mathrm{~mm}$ or that of FEP $\geq 18 \mathrm{~mm}$, the two antibiotics can be reported susceptibility for enterobacteriaceae, irrespective of the isolates producing ESBLs or not, according to the CLSI [10]. In all Shigella isolates studied, a similar results of resistance to CAZ and FEP (16.6\% and 18.5\%) were observed, which were higher than that reported by Yang et al. (5.2\% and 6.5\%) [16]. However, the resistance rates in Table 2 indicated that the two antibiotics were more suitable for the empiric therapy of the infection of ESC-resistant S. sonnei than that of ESC-resistant S. flexneri infection.

Fluoroquinolones are the popular antibiotics for the treatment of serious shigellosis in both adults and children. Research results from $\mathrm{Gu}$ et al. [23] showed the resistance rate to CIP was $29.1 \%$ between 2007 and 2009 in the Asia-Africa area. Data from Henan Province, China displayed that $21 \%$ and $79 \%$ of S. flexneri strains showed high- or low-level resistance to CIP, respectively [6]. Yang et al. [16] reported that 27.9\% and 9.7\% Shigella were resistance to CIP and LEV, respectively, in Anhui province, China. In our study, a similar resistance rate to CIP (24.2\%) and a higher resistance rate to LEV (16.0\%) were exhibited (Table 2). Among the fluoroquinolone resistant isolates, $95.3 \%$ (82/86, resistance to CIP) and 89.5\% (51/57, resistance to LEV) strains belonged to $S$. flexneri. The possible cause was that S. flexneri isolates often possessed plasmid-mediated quinolone resistance (PMQR) determinants or mutations in quinolone resistance-determining regions (QRDR) of gyrase and topoisomerase genes. This situation had been described in isolates from other regions of China by Zhang et al. [4], Zhu et al. [24] and Pu et al. [25].

So far, at least 109 variants of CTX-M enzymes (CTXM-1 to 124) have been described. Of these CTX-Ms, 19 variants (CTX-M-15, 16, 19, 23, 25, 27, 32, 35, 37, 40, $42,53,54,55,57,58,62,64,82,93)$ exhibit the increased hydrolysis activity against ceftazidime, and the others display a much higher rate of hydrolysis of cefotaxime than ceftazidime [26]. CTX-M-15 is the most usually detected CTX-M variant that hydrolyze ceftazidime at high level in enterobacteriaceae [26]. In this study, 28 bla $_{C T X-M-15}$ positive ESC-resistant Shigella isolates were all resistant to ceftazidime (data not shown). No other CTX-M variant genes mediating high level ceftazidime resistance were found (Table 3). In the bla $a_{C T X-M}$ genes with higher catalytic efficiencies against cefotaxime than ceftazidime, $b l a_{C T X-M-14}$ was the most prevalent one (53.0\%), and coincides with the data published worldwide in clinically important pathogens [26]. OXA-30 belongs to the class D oxacillinase group III, and mediates resistance to cefepime but not ceftazidime [27]. Unfortunately, $52(26.3 \%)$ of our ESC-resistant Shigella isolates hosted $b l a_{O X A-30}$, and 12 of them carried bla $a_{C T X-M-15}$ concomitantly and conferred resistance to cefotaxime, ceftazidime and cefepime (Table 3). In the past decade, an emergence of ESBL-producing Shigella spp. carrying different types of ESBL genes has been described in different countries and regions [28]. However, only a few studies have reported in the world the existence of AmpC $\beta$-lactamases encoded by bla $a_{C M Y-2}$ or bla $a_{D H A-1}$ in Shigella spp. [4,25,28-31]. In this study, we also found $2 \mathrm{AmpC} \beta$-lactamase producers with $b l a_{D H A-1}$ and $b l a_{C M Y-2}$ in the three-dimensional extract test positive Shigella strains. The $b l a_{C M Y-2}$ and the bla $a_{D H A-1}$ existed in $1 S$. flexneri with bla $a_{C T X-M-14}$ and $1 S$. sonnei with bla $_{C T X-M-15}$ and bla $a_{O X A-30}$, respectively (Table 3 ).

In this study, we detected several pathogenic genes (ial, ipaH, set1, sen and virA) for 198 ESC- resistant Shigella isolates (Table 4). It has been shown that ial 
takes responsibility for penetration of epithelial cell by Shigella and ipaH also for spread from cell to cell [32,33]. All Shigella species studied were positive for the $i p a H$ as expected because this gene exists in multiple copies on both the chromosome and the plasmid of Shigella. Conversely, the ial gene is exclusively located on the plasmid and was only detected in some Shigella isolates [8]. Indeed, less frequent examination of ial gene had been described by Luscher and Altwegg [34], Kingombe et al. [35] and Thong et al. [36]. However, this gene was found in all our ESC-resistant Shigella strains. Another virulence factor VirA is involved in the uptake, motility, and cell to cell transmission of Shigella within the human host. It is an essential virulence factor in Shigella disease pathogenesis [9]. The positive rate of virA implied all the isolates of our collection might have the ability (Table 4). The set 1 chromosomal gene encodes Shigella enterotoxin 1 (ShET-1, composed of one A and five B subunits), which is generated by $S$. flexneri (mainly in type 2a) and not found in other Shigella spp. [8,12,36-41]. The sen gene encoding Shigella enterotoxin 2 (ShET-2) is carried on a $140 \mathrm{MDa}$ virulence plasmid. And the sen is present in all Shigella species. The both toxins are deemed to play a part in the clinical manifestation of shigellosis [8]. In our study, $79.3 \%$ of ESC-resistant $S$. flexneri strains were found to be $\operatorname{set} 1 A$ and $\operatorname{set} 1 B$ positive $(62.1 \%$ isolates were serotype f2a, Table 4$)$, and this is agreement with the previous results; however, $17.1 \%(24 / 140)$ ESC-resistant S. sonnei isolates also carried set $1 A$ and/or set $1 B$ genes (Table 4 ). The set $1 A$ and set $1 B$ genes are located on the she pathogenicity island (PAI), a chromosomal, laterally acquired, integrative element of S. flexneri [37]. Integrase-mediated excision can occur for the she PAI, and result in the formation of a circular excision product, which is a substrate for lateral transfer processes e.g. conjugation, packaging into phage particles and recombinase-mediated integration into the chromosome [42]. This may be the cause that the two determinants can be found in our ESCresistant $S$. sonnei isolates studied. And the deficiency of set $1 A$ or set $1 B$, or the existence of point mutations in the primer binding sites may be the possible explanation for the both genes not coexisting in some ESC-resistant $S$. sonnei isolates (Table 4). Furthermore, we found that the $S$. flexneri isolates with set 1 were more resistance to CIP, LEV $(\mathrm{p}<0.001$, each $)$ and FEP $(\mathrm{p}=0.019)$ than those without set1; for $S$. sonnei, the set1 positive isolates were more likely resistance to SAM ( $\mathrm{p}<0.001)$, CIP, LEV ( $\mathrm{p}<0.001$, each) and FEP $(\mathrm{p}=0.002)$, and more likely sensitivity to CAZ $(\mathrm{p}=0.005)$ than set1 negative ones (data not shown). Nevertheless, we do not think there was correlation between set 1 and the antibiotics resistance, because none of reports have described currently that the invasion genetic elements carrying virulence genes known contain resistance determinants simultaneously in Shigella spp.. These resistance differences may be only due to the spread of resistant plasmids among the different strains.

The results of ERIC-PCR typing showed that most of the cases of ESC-resistant S. flexneri and S. sonnei infections were caused by several identical strains, respectively [for S. flexneri isolates, the percentage of type A and type B accounting for $63.8 \%$ (37/58); for S. sonnei, type A, type B and type C encompassing 69.3\% (97/140) of the isolates]. This indicates that clonal dissemination was likely to contribute most to the spread of ESC-resistant S. flexneri and $S$. sonnei within the region studied. Of 46 ESC-resistant $S$. flexneri isolates with the second largest number of the virulence gene composition $(i a 1+i p a H+v i r A+\operatorname{set} l A+$ setl $B+$ sen) being resistant to 4 to 8 antibiotics, $60.3 \%$ belonged to type A (43.1\%) and type B (17.2\%). Of 114 ESC-resistant $S$. sonnei isolates with the first largest number of the virulence gene composition $(i a 1+i p a H+$ vir + sen) being resistant to 3 to 6 antibiotics, $71.1 \%$ belonged to type A (57.9\%) and type B (13.2\%), but isolates that hosted the set1 gene were more heterogeneous in ERIC-PCR pattern.

In the present study all the Shigella strains were isolated from intestinal clinic patients. No patients had been hospitalized or died following episodes of shigellosis. According to the clinical reports, early stage of shigellosis the patients infected by ESBL genes positive isolates were not more severe than those of the patients infected by ESBL genes negative isolates. However, most of these patients had longer course of treatment, because physicians used to treat diarrhea by prescribing cefotaxime or ceftriaxone (particularly for children) in the region studied. When treatment failed, other drugs (such as fluoroquinolone or $\beta$-lactamase inhibitors) would be used as a substitute for continuing treatment. In addition, all the patients with Shigella infection in the study were treated with antibiotics, therefore, we had no relevant data to compare the course of disease treated using antibiotics with that of disease treated without antibiotics.

\section{Conclusions}

This investigation found a striking difference from other regions of China with relatively low economic status in the distribution of species, from S. flexneri to S. sonnei, and a high prevalence of ESC-resistance among Shigella isolates. Antibiotic susceptibility testing displayed ESCresistant $S$. flexneri isolates were much more resistant than ESC-resistant S. sonnei isolates. The analysis of extendedspectrum cephalosporin resistance genes showed the spread of the Shigella harboring a combination of genes bla $a_{C T X-M-15}$ and $b l a_{O X A-30}$. This combination may be a serious threat to infection treatment because it is spread by conjugation and it displays high levels of resistance to cefotaxime, ceftazidime and cefepime. We also described the 
prevalence of virulence genes in ESC-resistant Shigella, which may provide clues about the pathogenicity difference of this type of bacteria. ERIC-PCR typing supported the existence of specific clones responsible for the ESCresistant S. flexneri and S. sonnei infection cases in the region studied. In China, especially in some undeveloped regions, there were limited and sporadic data on the epidemiology of Shigella spp. Therefore, we suggest the Ministry of Health National Antimicrobial Resistance Investigation Net (Mohnarin) to reinforce the surveillance for the development of antibiotic resistance and take measures to control shigellosis in China.

\section{Abbreviations \\ ESC: Extended-spectrum cephalosporin; ESBL: Extended-spectrum beta-lactamase; S. flexneri: Shigella flexneri; S. sonnei: Shigella sonnei; CLSI: Clinical laboratory standards institute; PCR: Polymerase chain reaction; ERIC-PCR: Enterobacterial repetitive intergenic consensus sequence polymerase chain reaction; SPSS: Statistical package for social sciences.}

\section{Competing interests}

The authors declare no conflict of interests.

\section{Authors' contributions}

CLZ performed the experiments; QZL designed the study, analyzed the clinical data and wrote this manuscript; JW, XC, LMS and YYG collected the clinical samples. All authors read and approved the final manuscript.

\section{Acknowledgments}

The authors thank Yunkui Zong for critical review of the manuscript. This work was supported by grants from Natural Science Foundation, Science and Technology Commission of Shanghai (No. 12ZR1425000), the National Natural Science Foundation of China (No. 81371872), and Xiaoshan District, Major Scientific and Technological Research Projects (No. 2013314).

\section{Author details}

'Department of Clinical Laboratory, Zhejiang Xiaoshan Hospital, Zhejiang Province, China. ${ }^{2}$ Department of Clinical Laboratory, Shanghai First People's Hospital, School of Medicine, Shanghai Jiaotong University, 100 Haining Road, Shanghai 200080, People's Republic of China.

Received: 7 December 2013 Accepted: 8 May 2014

Published: 15 May 2014

\section{References}

1. Kuo CY, Su LH, Perera J, Carlos C, Tan BH, Kumarasinghe G, So T, Van PH, Chongthaleong A, Song $\mathrm{JH}$, Chiu CH: Antimicrobial susceptibility of Shigella isolates in eight Asian countries, 2001-2004. J Microbiol Immunol Infect 2008, 41:107-111.

2. Wang XY, Tao F, Xiao D, Lee H, Deen J, Gong J, Zhao Y, Zhou W, Li W, Shen B, Song Y, Ma J, Li ZM, Wang Z, Su PY, Chang N, Xu JH, Ouyang PY, von Seidlein L, Xu ZY, Clemens JD: Trend and disease burden of bacillary dysentery in China (1991-2000). Bull World Health Organ 2006, 84:561-568.

3. Ji WJ, Xu XW, Dong F: Genotype and drug resistance analysis of extended-spectrum beta-lactamases-producing Shigella in pediatric patients. Chin J Microbiol Immunol 2010, 30:472-476 (in Chinese).

4. Zhang W, Luo Y, Li J, Lin L, Ma Y, Hu C, Jin S, Ran L, Cui S: Wide dissemination of multidrug-resistant Shigella isolates in China. J Antimicrob Chemother 2011, 66:2527-2535.

5. Zhang R, Zhou HW, Cai JC, Zhang J, Chen GX, Nasu M, Xie XY: Serotypes and extended-spectrum $\beta$-lactamase types of clinical isolates of Shigella spp. from the Zhejiang province of China. Diagn Microbiol Infect Dis 2011, 69:98-104.

6. Xia S, Xu B, Huang L, Zhao JY, Ran L, Zhang J, Chen H, Pulsrikarn C, Pornruangwong S, Aarestrup FM, Hendriksen RS: Prevalence and characterization of human Shigella infections in Henan Province, China, in 2006. J Clin Microbiol 2011, 49:232-242.
7. Xiong Z, Li T, Xu Y, Li J: Detection of CTX-M-14 extended-spectrum beta-lactamase in Shigella sonnei isolates from China. J Infect 2007, 55:e125-e128.

8. Sousa MÂ, Mendes EN, Collares GB, Péret-Filho LA, Penna FJ, Magalhães PP: Shigella in Brazilian children with acute diarrhoea: prevalence, antimicrobial resistance and virulence genes. Mem Inst Oswaldo Cruz 2013, 108:30-35.

9. Yoshida S, Handa Y, Suzuki T, Ogawa M, Suzuki M, Tamai A, Abe A, Katayama E, Sasakawa C: Microtubule-severing activity of Shigella is pivotal for intercellular spreading. Science 2006, 314:985-989.

10. Clinical and Laboratory Standards Institute: Performance standards for antimicrobial susceptibility testing; Twenty-second Informational supplement, Document M100-S22. Wayne, PA: CLSI; 2012.

11. Coudron PE, Moland ES, Thomson KS: Occurrence and detection of AmpC beta-lactamases among Escherichia coli, Klebsiella pneumoniae, and Proteus mirabilis isolates at a Veterans Medical Center. J Clin Microbiol 2000, 38:1791-1796.

12. Vargas M, Gascon J, Jimenez De Anta MT, Vila J: Prevalence of Shigella enterotoxins 1 and 2 among Shigella strains isolated from patients with traveler's diarrhea. J Clin Microbiol 1999, 37:3608-3611.

13. Villalobo E, Torres A: PCR for detection of Shigella spp. in Mayonnaise. Appl Environ Microbiol 1998, 64:1242-1245.

14. Pérez-Pérez FJ, Hanson ND: Detection of plasmid-mediated AmpC-lactamase genes in clinical isolates by using mitiplex PCR. J Clin Microbiol 2002, 40:2153-2162.

15. Kumao T, Ba-Thein W, Hayashi H: Molecular subtyping methods for detection of Salmonella enterica serovar Oranienburg outbreaks. J Clin Microbiol 2002, 40:2057-2061.

16. Yang H, Chen G, Zhu Y, Liu Y, Cheng J, Hu L, Ye Y, Li J: Surveillance of antimicrobial susceptibility patterns among Shigella species isolated in China during the 7-year period of 2005-2011. Ann Lab Med 2013, 33:111-115.

17. Shen Y, Qian H, Gong J, Deng F, Dong C, Zhou L, Guo H: High prevalence of antibiotic resistance and molecular characterization of integrons among Shigella isolates in Eastern China. Antimicrob Agents Chemother 2013, 57:1549-1551.

18. Chang Z, Lu S, Chen L, Jin Q, Yang J: Causative species and serotypes of shigellosis in mainland China: systematic review and meta-analysis. PLOS ONE 2012, 7:e52515.

19. von Seidlein L, Kim DR, Ali M, Lee H, Wang X, Thiem VD, Canh do G, Chaicumpa W, Agtini MD, Hossain A, Bhutta ZA, Mason C, Sethabutr O, Talukder K, Nair GB, Deen JL, Kotloff K, Clemens J: A multicentre study of Shigella diarrhoea in six Asian countries: disease burden, clinical manifestations, and microbiology. PLoS Med 2006, 3:e353.

20. Vinh H, Nhu NT, Nga TV, Duy PT, Campbell II, Hoang NV, Boni MF, My PV, Parry C, Nga TT, Van Minh P, Thuy CT, Diep TS, Phuong le T, Chinh MT, Loan HT, Tham NT, Lanh MN, Mong BL, Anh VT, Bay PV, Chau NV, Farrar J, Baker S: A changing picture of shigellosis in southern Vietnam: shifting species dominance, antimicrobial susceptibility and clinical presentation. BMC Infect Dis 2009, 9:204.

21. Seol SY, Kim YT, Jeong YS, Oh JY, Kang HY, Moon DC, Kim J, Lee YC, Cho DT, Lee JC: Molecular characterization of antimicrobial resistance in Shigella sonnei isolates in Korea. J Med Microbiol 2006, 55:871-877.

22. Wei HL, Wang YW, Li CC, Tung SK, Chiou CS: Epidemiology and evolution of genotype and antimicrobial resistance of an imported Shigella sonnei clone circulating in central Taiwan. Diagn Microbiol Infect Dis 2007, 58:469-475.

23. Gu B, Cao Y, Pan S, Zhuang L, Yu R, Peng Z, Qian H, Wei Y, Zhao L, Liu G, Tong M: Comparison of the prevalence and changing resistance to nalidixic acid and ciprofoxacin of Shigella between Europe-America and Asia-Africa from 1998 to 2009. Int J Antimicrob Agents 2012, 40:9-17.

24. Zhu YL, Yang HF, Liu YY, Hu LF, Cheng J, Ye Y, Li JB: Detection of plasmid-mediated quinolone resistance determinants and the emergence of multidrug resistance in clinical isolates of Shigella in SiXian area, China. Diagn Microbiol Infect Dis 2013, 75:327-329.

25. Pu XY, Pan JC, Wang HQ, Zhang W, Huang ZC, Gu YM: Characterization of fluoroquinolone-resistant Shigella flexneri in Hangzhou area of China. J Antimicrob Chemother 2009, 63:917-920.

26. Zhao $\mathrm{WH}, \mathrm{Hu}$ ZQ: Epidemiology and genetics of CTX-M extended-spectrum $\beta$-lactamases in Gram-negative bacteria. Crit Rev Microbiol 2013, 39:79-101.

27. Dubois V, Arpin C, Quentin C, Texier-Maugein J, Poirel L, Nordmann P: Decreased susceptibility to cefepime in a clinical strain of Escherichia coli related to plasmid- and integron-encoded OXA-30 beta-lactamase. Antimicrob Agents Chemother 2003, 47:2380-2381. 
28. Taneja N, Mewara A, Kumar A, Verma G, Sharma M: Cephalosporin-resistant Shigella flexneri over 9 years (2001-09) in India. J Antimicrob Chemother 2012, 67:1347-1353.

29. Livermore DM, Mushtaq S, Nguyen T, Warner M: Strategies to overcome extended-spectrum $\beta$-lactamases (ESBLs) and AmpC $\beta$-lactamases in shigellae. Int J Antimicrob Agents 2011, 37:405-409.

30. Huang IF, Chiu CH, Wang MH, Wu CY, Hsieh KS, Chiou CC: Outbreak of dysentery associated with ceftriaxone-resistant Shigella sonnei: First report of plasmid-mediated CMY-2-type AmpC beta-lactamase resistance in S. sonnei. J Clin Microbiol 2005, 43:2608-2612.

31. Tajbakhsh M, García Migura L, Rahbar M, Svendsen CA, Mohammadzadeh M, Zali MR, Aarestrup FM, Hendriksen RS: Antimicrobial-resistant Shigella infections from Iran: an overlooked problem? J Antimicrob Chemother 2012, 67:1128-1133.

32. Wei J, Goldberg MB, Burland V, Venkatesan MM, Deng W, Fournier G, Mayhew GF, Plunkett G 3rd, Rose DJ, Darling A, Mau B, Perna NT, Payne SM, Runyen-Janecky $L$, Zhou S, Schwartz DC, Blattner FR: Complete genome sequence and comparative genomics of Shigella flexneri serotype 2a strain 2457T. Infect Immun 2003, 71:2775-2786.

33. Parsot C: Shigella spp and enteroinvasive Escherichia coli pathogenicity factors. FEMS Microbiol Lett 2005, 252:11-18.

34. Lüscher D, Altwegg M: Detection of shigellae, enteroinvasive and enterotoxigenic Escherichia coli using the polymerase chain reaction (PCR) in patients returning from tropical countries. Mol Cell Probes 1994, 8:285-290.

35. Kingombe $\mathrm{Cl}$, Cerqueira-Campos $\mathrm{ML}$, Farber JM: Molecular strategies for the detection, identification, and differentiation between enteroinvasive Escherichia coli and Shigella spp. J Food Prot 2005, 68:239-245.

36. Thong KL, Hoe SL, Puthucheary SD, Yasin R: Detection of virulence genes in Malaysian Shigella species by multiplex PCR assay. BMC Infect Dis 2005, $5: 8$

37. Niyogi SK, Vargas M, Vila J: Prevalence of the sat, set and sen genes among diverse serotypes of Shigella flexneri strains isolated from patients with acute diarrhoea. Clin Microbiol Infect 2004, 10:574-576.

38. Noriega FR, Liao FM, Formal SB, Fasano A, Levine MM: Prevalence of Shigella enterotoxin 1 among Shigella clinical isolates of diverse serotypes. J Infect Dis 1995, 172:1408-1410.

39. Yavzori M, Cohen D, Orr N: Prevalence of the genes for Shigella enterotoxins 1 and 2 among clinical isolates of Shigella in Israel. Epidemiol Infect 2002, 128:533-535.

40. Roy S, Thanasekaran K, Dutta Roy AR, Sehgal SC: Distribution of Shigella enterotoxin genes and secreted autotransporter toxin gene among diverse species and serotypes of shigella isolated from Andaman Islands, India. Trop Med Int Health 2006, 11:1694-1698.

41. Farfán MJ, Garay TA, Prado CA, Filliol I, Ulloa MT, Toro CS: A new multiplex PCR for differential identification of Shigella flexneri and Shigella sonnei and detection of Shigella virulence determinants. Epidemiol Infect 2010, 138:525-533.

42. Sakellaris H, Luck SN, Al-Hasani K, Rajakumar K, Turner SA, Adler B: Regulated site-specific recombination of the she pathogenicity island of Shigella flexneri. Mol Microbiol 2004, 52:1329-1336.

doi:10.1186/1471-2334-14-260

Cite this article as: Zhang et al:: Epidemic and virulence characteristic of Shigella spp. with extended-spectrum cephalosporin resistance in Xiaoshan District, Hangzhou, China. BMC Infectious Diseases

\section{Submit your next manuscript to BioMed Central and take full advantage of:}

- Convenient online submission

- Thorough peer review

- No space constraints or color figure charges

- Immediate publication on acceptance

- Inclusion in PubMed, CAS, Scopus and Google Scholar

- Research which is freely available for redistribution 